\title{
Face-to-face versus distance learning in a seaside area: the teacher's point of view
}

\section{Antonella Centonze ${ }^{1}$, Rosa Anfosso ${ }^{2}$, Roberta Pujia ${ }^{3}$, Stefania Zampogna ${ }^{4}$, Domenico Sinopoli $^{5}$, Ilaria Prosperi Porta ${ }^{6}$, Emanuele Baldassarre ${ }^{7}$}

\author{
${ }^{1}$ Department of Paediatric Surgery, Pugliese-Ciaccio Hospital, Catanzaro, Italy \\ ${ }^{2}$ Department of Health Promotion ASP, Catanzaro, Italy \\ ${ }^{3}$ Department of Medical Sciences, University of Catanzaro "Magna Grecia", Italy \\ ${ }^{4}$ Department of Paediatric, Pugliese-Ciaccio Hospital, Catanzaro, Italy \\ ${ }^{5}$ Department of Oncology, Pugliese-Ciaccio Hospital, Catanzaro, Italy \\ ${ }^{6}$ Department of Emergency Medicine, ASL Valle d'Aosta, Italy \\ ${ }^{7}$ Department of Andrology and Paediatric Urology, ASL Valle d'Aosta, Italy
}

\begin{abstract}
The total or partial replacement of face-to-face teaching with distance teaching brings a number of problems for teachers, children and families. Recently, in our province in Southern Italy, in a seaside area, we conducted a survey to assess the experiences of high school teachers faced with distance learning during the COVID-19 pandemic, with the purpose of examining the real impact of these dramatic changes, both from social and health perspectives. From the preliminary aspects of this survey it emerges that it is difficult to univocally consider the effectiveness of distance learning in such a complex territory, especially in a seaside area. This experience will serve us to reflect in the future on a school tailored to the individual student by a permanent integration of face-to-face forms with distance learning.
\end{abstract}

(Int Marit Health 2021; 72, 3: 193-194)

Key words: COVID-19, distance learning, survey, seaside area

Recently we read some recently published articles about the effects of the pandemic on the school population, such as education loss, increasing mental health disorders, lack of physical activity, possibly developing negative behaviours up to violence and abuse [1]. The total or partial replacement of face-to-face teaching with distance teaching brings a number of problems for teachers, children and families. From worldwide experience, the main reported problems are: the lack of teacher's authority, the socioeconomic gap of children who are economically deprived and with difficulties in accessing online education, like the availability of a computer suitable for education, internet access, difficulties in concentrating in the crowded home environment [2, 3].

Recently, in our province in Southern Italy, in a seaside area, we conducted a survey to explore the experi- ences of high school teachers faced with distance learning during the coronavirus disease 2019 (COVID-19) pandemic, with the purpose of examining the real impact of these dramatic changes, both from social and health perspectives. A questionnaire containing 18 questions, closed-ended and multiple-choice, were administered to the teachers of 4 high schools of Catanzaro city (I) and province, for a total of 167 persons. 54\% of teachers belonged to a humanistic/linguistic area, $27 \%$ scientific and technological, $8 \%$ historical-social-religious, $11 \%$ mixed. Almost all of the teachers (98\%) activated the distance learning using video and audio lessons, giving homework, questionnaires and online tests. $75 \%$ of the teachers used films and documentaries. The distance learning dialogue with students is judged good by $47 \%$, teachers, sufficient by $40 \%$, insufficient/medium by $8 \%$ and excellent by only 
$5 \%$ of teachers. The scholastic commitment of the children was judged excellent by $4 \%$, good by $45 \%$, sufficient by $49 \%$ and totally insufficient by $6 \%$ of the teachers. $44 \%$ of teachers did not prepare specific activities or materials for students with special educational needs. The main highlighted problems in the teacher-student relationship were the difficulty of communication (30\%), difficulty in interaction with the individual student and with the class group (30\%). A consequent lack of interest and motivation was reported in $28 \%$ of interviewed teachers. The commonest reported technical difficulties were the slow or insufficient internet connection (39\%), lack of scholastic guidelines and clear references (11\%), and for a small percentage difficulty in using the tools and lack of a computer or tablet (4\%). In conclusion, $54 \%$ of teachers affirmed to have totally revised the teaching methods, while $19 \%$ have tried to adapt them.

In light of the raw data emerging from this interview, it appears a great effort has been made by the teachers to adapt themselves to the situation in a short time. Beyond the technical aspects, such as the lack of homogeneity in the territory of the internet connection and the specific skills, the more relevant aspect is the difficulty in building a tailored approach for the single realities within a school, or even for the single students within a single class. However, it remains utopian to create common guidelines worldwide. Within a single region or nation, as in our case, there is an extreme differentiation and different degrees of experience and resilience of the student population. In developed western states, countries with a low population density such as the United States or Australia have a greater confidence in distance learning than European realities such as the Italian one. Another very important aspect for distance learning is represented by the geographical characteristics of the territory. In our area there is a lot of unevenness as it passes from mountainous areas that are difficult to access to port and marine areas.

Our region has some peculiarities compared to the Italian territory and the presence of distance learning requires a considerable investment of public funds. Unlike many regions of a more industrial nature in Central and Northern Italy, the territory completely interfaces with the social fabric typical of port cities and mass summer tourism. The investment of public funds for the school system should protect above all the most disadvantaged areas, characterized by migratory phenomena.

This experience will serve us to reflect in the future on a school tailored to the individual student by a permanent integration of face-to-face forms with distance learning.

Conflict of interest: None declared

\section{REFERENCES}

1. Hacımustafaoğlu M. COVID-19 and re-opening of schools: Opinions with scientific evidence. Turk Pediatri Ars. 2020; 55(4): 337-344, doi: 10.14744/TurkPediatriArs.2020.90018, indexed in Pubmed: 33414650.

2. Fantini MP, Reno C, Biserni GB, et al. COVID-19 and the re-opening of schools: a policy maker's dilemma. Ital J Pediatr. 2020; 46(1): 79, doi: 10.1186/s13052-020-00844-1, indexed in Pubmed: 32517815.

3. Lakha F, King A, Swinkels K, et al. Are schools drivers of COVID-19 infections-an analysis of outbreaks in Colorado, USA in 2020. J Public Health (Oxf). 2021 [Epub ahead of print], doi: 10.1093/pubmed/ fdab213, indexed in Pubmed: 34179987. 